\title{
The maze IV operation is not always the best choice: Matching the procedure to the patient
}

\section{Patrick M. McCarthy, MD}

Surgery for atrial fibrillation (AF) has long been a work in progress. The earliest iterations from the 1980s included left atrial (LA) isolation, atrial transection, and the corridor procedure. ${ }^{1-3}$ The corridor procedure created a pathway (ie, corridor) from the sinoatrial node to the atrioventricular node but did not innervate the rest of the atria, and therefore patients continued in $\mathrm{AF}$. Isolation and transection were also not designed to ablate AF, just to isolate it. After extensive laboratory investigation, the maze procedure was designed by Dr James L. Cox to ablate $\mathrm{AF}$, maintain atrioventricular synchrony, innervate both atria, and excise (or close) the left atrial appendage (LAA). These 4 fundamental concepts continue today. The maze procedure itself has evolved over time from maze I, to maze II, and eventually to what we now refer to as the Cox-maze III procedure (sometimes referred to as the cut-and-sew maze). After the introduction of bipolar radiofrequency (RF) clamps, the maze IV was developed with the goal to simplify the technique and make it faster. ${ }^{4}$ Eventually, bipolar RF clamps were approved by the Food and Drug Administration and labeled specifically for AF ablation, which is why industry is allowed to educate surgeons about the use of the clamps and AF surgery. ${ }^{5}$ But, the maze IV is still complex and adds cardiopulmonary bypass (CPB) time and morbidity such as need for new pacemakers and renal dysfunction. ${ }^{5-10}$ Furthermore, based on electrophysiology studies showing AF triggers arising primarily at the pulmonary vein-LA junction, sometimes only bilateral pulmonary vein isolation (PVI) is performed using bipolar RF clamps. ${ }^{11,12}$ Although PVI was almost as good as a maze IV in a randomized trial, further analysis showed less effectiveness. ${ }^{12}$ Electrophysiology studies as the basis of PVI were relevant to lone AF, but patients with underlying structural heart disease (such as valve disease) have a different pathophysiology. ${ }^{11}$

\footnotetext{
From the Division of Cardiac Surgery, Department of Surgery, Bluhm Cardiovascular Institute, Northwestern University Feinberg School of Medicine and Northwestern Medicine, Chicago, Ill.

Received for publication April 12, 2021; accepted for publication June 24, 2021; available ahead of print June 29, 2021

Address for reprints: Patrick M. McCarthy, MD, Division of Cardiac Surgery, Department of Surgery, Bluhm Cardiovascular Institute, Northwestern University Feinberg School of Medicine, 676 N Saint Clair St, Arkes Family Pavilion, Suite 730, Chicago, IL 60611 (E-mail: Patrick.McCarthy@nm.org).

JTCVS Techniques 2023;17:79-83

2666-2507

Copyright (C) 2021 The Author(s). Published by Elsevier Inc. on behalf of The American Association for Thoracic Surgery. This is an open access article under the CC BY-NC-ND license (http://creativecommons.org/licenses/by-nc-nd/4.0/). https://doi.org/10.1016/j.xjtc.2021.06.031
}

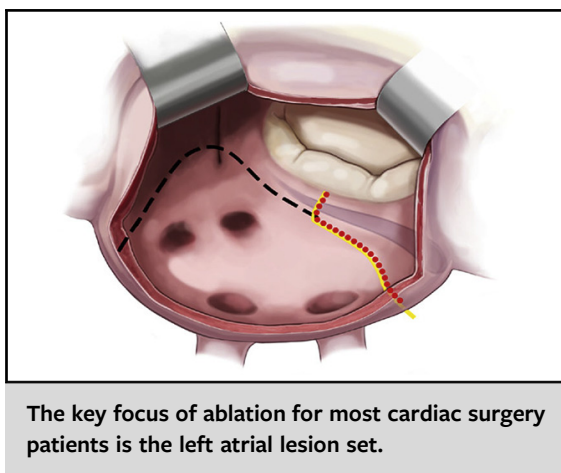

\begin{abstract}
CENTRAL MESSAGE
Numerous variations of AF surgery have been developed over 30 years and ablation concomitant with cardiac procedures is advised when safe. Matching the extent of ablation to the patient makes sense.
\end{abstract}

In addition to lesion sets, the technology that creates transmural lesions has evolved. There was never a concern with transmural ablation with the cut-and-sew technique because the electrical wavefront cannot transmit across the suture line. Cryoablation is required for portions of the maze I through IV procedures and creates reliable transmural lesions (Figure 1). ${ }^{13}$ Bipolar RF also creates reliable lesions. Disposable tools-using cryoprobes with or without bipolar RF-are used in the majority of AF surgical ablations in the United States. Over time, other energy sources such as microwaves, high-intensity-focused ultrasound, laser, and bipolar cryoablation clamps have come and gone. Unipolar RF is still available, but creating transmural lesions is not reliable.

An important aspect of AF ablation surgery that should be emphasized is the LAA closure. Originally, this was accomplished by LAA excision or various suture closure techniques. Staplers were eventually used, and a clip was commercially released that is simple to use, consistently successful, and it electrically isolates the LAA. ${ }^{14,15}$ Notably, a database study of Medicare patients showed improved late survival and freedom from stroke for AF patients undergoing cardiac surgery who had LAA closure. ${ }^{16}$ Also, a study of LAA closure in AF patients, the Left Atrial 


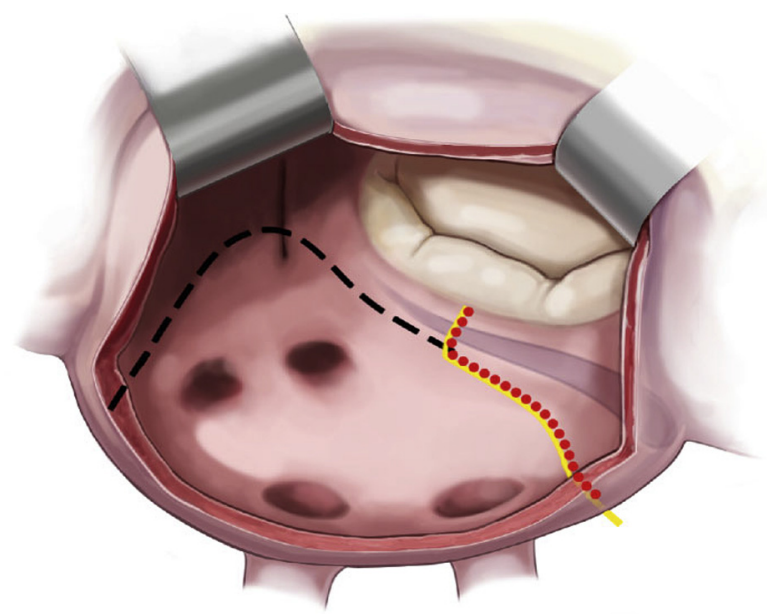

FIGURE 1. The left atrial lesion set. The most important focus of ablation for almost all cardiac surgery patients is the left side lesion set. At Northwestern Medicine, we start with epicardial clip application to the left atrial appendage, which also electrically isolates the appendage. Only in the case of extensive pericardial adhesions do we close the left atrial appendage internally. The first 3-minute cryolesion (dashed black line) uses a disposable probe from the superior extent of the atriotomy across the dome of the left atrium, and the base of the appendage, and typically ends at about the P2 location. The second 3-minute cryolesion (red dotted line) extends from the inferior atriotomy, across the end of lesion 1 to complete the box lesion, and the probe is bent to create the mitral annular lesion. The third 2-minute cryolesion (yellow line) is applied on the epicardium across the coronary sinus.

Appendage Occlusion Study, randomized 4811 patients and found late reduction of stroke for those with LAA closure compared with those without LAA treatment $(7.0 \%$ vs $4.8 \% ; P=.001) .{ }^{17}$ Only $34.0 \%$ and $31.5 \%$ underwent concomitant surgical ablation.

\section{NORTHWESTERN MEDICINE APPROACH TO CONCOMITANT ABLATION}

AF surgery may appear to be chaotic because there are many lesion sets, techniques, and technologies (often used in combination) and ardent supporters of each. ${ }^{18,19}$ Patients with preoperative $\mathrm{AF}$ are frequently elderly with comorbidities, and the primary cardiac surgery indication (eg, valve or coronary artery bypass) is almost invariably the focus of the operation. Concomitant AF ablation is a secondary goal. Here, we summarize our approach at Northwestern Medicine. First, we try to treat as many patients as we can with preoperative AF because a variety of studies have shown improved late survival for AF-treated patients. ${ }^{20-23}$ Other centers and surgeons are more selective, and may not treat patients with known risk factors for failure (eg, large LA or long duration of $\mathrm{AF}$ ), but our approach is more inclusive. ${ }^{6,7}$ Second, adding ablation must be safe (primum non nocere). Generally, Society of Thoracic Surgeons reports and single-center reports show little difference in perioperative outcomes between AF-treated and untreated patients, except for higher need for pacemakers and renal dysfunction. ${ }^{8,24,25}$ As with all matched studies, the untreated group may include unmeasured confounders (eg, frailty) that could influence outcomes. And although some think the increased need for pacemakers is benign, the late outcomes from the Cardiothoracic Surgery Network (CTS Net) randomized trial showed a higher mortality for those who needed a pacemaker. ${ }^{26}$

To achieve our goal to treat as many patients as possible but minimize morbidity, we avoid prolonged CPB time and avoid ablation or incisions that may increase the need for pacemakers. ${ }^{27}$ We do that by matching the amount of ablation and LAA closure to the patient and the primary cardiac operation. Our approach has evolved along with our experience and as more reports appeared. In rank order (Table 1), reducing stroke risk is our top priority for concomitant AF surgical ablation, so LAA closure is performed as often as possible, even if there is no intent to perform AF ablation. Originally, we did this with internal or external closure of the LAA. But studies indicated a high degree of failure and $>10 \mathrm{~mm}$ residual stump. ${ }^{14}$ We were skeptical and performed our own randomized trial, and found similar results. $^{28}$ Therefore, we switched to using a commercial clip that has a near $100 \%$ successful occlusion rate, and it electrically isolates the LAA so there is no need for additional LAA ablation lines. ${ }^{15,29,30}$ Although this is an added expense compared with suture or stapler LAA occlusion, it is more effective and preventing stroke is among the most important goals of AF surgical treatment. Only in rare circumstances, in very-high-risk patients with little chance of successful ablation, would we only treat the LAA without at least LA ablation.

TABLE 1. Hierarchy of atrial fibrillation ablation treatment for adaptation to patient and procedure*

\begin{tabular}{ll}
\hline \multicolumn{1}{c}{ Lesion location } & \multicolumn{1}{c}{ Treatment } \\
\hline Left atrial appendage & Epicardial clip, or securely close in 2 layers \\
Left atrium lesions & $\begin{array}{l}\text { Box lesion } \\
\text { Left atrial appendage base } \\
\text { Mitral annular line } \\
\text { Coronary sinus }\end{array}$ \\
& $\begin{array}{l}\text { Right atriotomy to tricuspid annulus } \\
\text { Atriotomy to superior vena cava } \\
\text { Right atrium lesions }\end{array}$ \\
& Atriotomy to inferior vena cava \\
\hline
\end{tabular}

*The highest priority is left atrial appendage closure to reduce the risk of late stroke. Unusual patients with very high risk due to comorbidities, and a low chance for ablation success, may be treated with left atrial appendage clip alone, but this is rare in our experience. The second highest priority is to treat the left atrium, which is typically dilated and abnormal in mitral valve and most other concomitant operations. For the vast majority of patients, and near $100 \%$ of mitral patients, a complete left atrial lesion set is added using only 3 cryoablation lesions. For patients without significant comorbidities and with right atrial dilatation, tricuspid valve pathology, long standing persistent or symptomatic atrial fibrillation, then 3 right atrial cryolesions are added to complete a biatrial lesion set. This may increase the need for a pacemaker and extends the cardiopulmonary bypass time, so it is not used in most patients referred for early mitral intervention. 
Second, the LA is the location of the pathology in patients with mitral disease and many other patients, and is the driver of AF. Therefore, an LA lesion set is used that includes a box lesion that encompasses the base of the LAA, a mitral annular line, and an epicardial coronary sinus ablation. We found acceptable results using PVI with bipolar RF clamps with aortic valve replacement operations, ${ }^{31}$ but unlike the CTS Net trial, we never used PVI alone for mitral surgery. For mitral reoperations we used internal cryoablation for years in a pattern similar to that described below, and eventually we compared those results to bipolar RF results (unpublished data). There was no difference in results, so since 2013 we have used cryoablation almost exclusively for mitral surgery. It is quicker and easier, and does not require dissection around the left pulmonary veins, which is hard to do with the small skin incisions we use routinely.

Third, for most patients with right-side pathology (eg, right atrial dilation or tricuspid regurgitation) and/or clinical factors (eg, young patient, symptomatic AF, or longstanding persistent $\mathrm{AF}$ ), we may add a right atrial (RA) lesion set. Omitting RA ablation is a tradeoff between the risks of more $\mathrm{CPB}$ time and higher pacemaker risk versus decreased freedom from AF effectiveness. ${ }^{18,32}$ The CTS Net trial also showed an association between pacemaker use and late mortality. ${ }^{10}$ But, if there is a failure only from the omission of right-sided lesions, those may be easily handled later with catheter ablation.

\section{LA-ONLY ABLATION OPERATIONS (MITRAL VALVE)}

While cardioplegia is being administered, the LA is opened in Waterston's groove. As soon as antegrade cardioplegia is complete, the heart is elevated and a clip is applied under direct vision to the base of the LAA and away from the circumflex coronary artery. A selfretaining mitral retractor is placed and a 3-minute cryolesion is placed from the superior aspect of the atriotomy, across the LA dome and the base of the LAA, and along the left midwall of the LA. Typically, the flexible cryoprobe is bent into a $C$ shape for this application and the tip of the probe is approximately at the level P2. After thawing, the cryoprobe is adjusted to an $L$ shape at the last $3 \mathrm{~cm}$ of the probe. The second 3-minute freeze starts at the inferior end of the atriotomy, extends along the inferior LA wall until it overlaps the end of the prior lesion, and the bent $3 \mathrm{~cm}$ of the probe crosses the mitral annulus and posterior leaflet at approximately P2. After thawing, the probe (in the same shape) is placed on the epicardium through the transverse sinus underneath the inferior vena cava and ablates the coronary sinus (which was already partially ablated by the second freeze). This third and final freeze is only a 2-minutes duration because the coronary sinus was already partially frozen (Figure 1). During the freezes, the mitral valve inspection begins and it may be possible to place some sutures. This minimizes crossclamp and CPB time. The ablation itself takes 8 minutes ( 2 cryoablations for $3 \mathrm{mi}-$ nutes; 1 cryoablation for 2 minutes).

\section{BIATRIAL ABLATION: RA LESIONS}

After the LA portion of the procedure is complete and the LA incision is closed, then a vertical or transverse right atriotomy is performed (about $3 \mathrm{~cm}$ long for tricuspid valve surgery and $1.5 \mathrm{~cm}$ for ablation only). The first 3-minute freeze extends from the right atriotomy across the inferior RA wall along the posterior tricuspid leaflet (usually for about $1 \mathrm{~cm}$ ) and ends with the tip of the cryoprobe inside the coronary sinus. The crossclamp is then removed and the last 2 lesions are created as the heart resumes function. A sucker in the RA evacuates the blood returning from the coronary sinus to minimize warm blood touching the probe. One 2-minute freeze extends from the right atriotomy into the inferior vena cava. The third and final 3-minute freeze extends from the right atriotomy up to the superior vena cava. This ablation line crosses the crista terminalis, which is thicker than the surrounding RA wall.

Proper application of the cryoprobe is needed to ensure a transmural freeze. Technical tips to improve probe contact without gaps include direct visualization of the probe against the atrial surface with steady pressure until the freeze holds the probe in place. This may be facilitated by releasing tension on the retractor blades and applying pressure from the outside (epicardial surface) using a sucker, sponge, or another tool. Occasionally, an epicardial touchup freeze is needed on the crista terminalis or on the endocardial lesions at a thick area of atrial tissue that does not seem to be completely ablated, or if any gap is identified when the probe is removed.

\section{LA-CLOSED OPERATIONS (CORONARY ARTERY BYPASS, AORTIC VALVE REPLACEMENT)}

For straightforward cases in healthy patients we do not hesitate to open the LA to do the complete box lesion, including the LAA base, mitral line, and coronary sinus epicardial ablation as described above. It adds a few minutes to open and close the left atrium but provides an extensive lesion set. The preference of other surgeons (we have done this in the past) is to use bipolar RF clamps to only isolate the left- and right-side pulmonary veins without opening the LA. With manipulation of the clamp you might be able to cross the lesions posteriorly and get more posterior LA wall ablated, but this does not treat the LAA base, mitral annulus, or coronary sinus. In addition, we typically use small sternotomy incisions and manipulating the clamp for PVI may be difficult and time-consuming through a small incision. In some complex cases in patients with comorbidities (eg, aortic valve surgery with aneurysm and coronary artery bypass), we may only close the LAA with a clip. For other patients, especially reoperations and those 
with comorbidities, including renal dysfunction, making a surgical judgment to not treat the AF and LAA may be appropriate.

\section{CONCLUSIONS}

The Cox-maze IV was the lesion set used when industry received Food and Drug Administration approval to market bipolar RF clamps specifically for AF ablation. ${ }^{5}$ Therefore, the clamps and the lesion set are marketed currently but there are many alternatives. Prospective multicenter studies with this approach have shown lower freedom from atrial fibrillation than most single-center reports, ${ }^{5,33}$ a high use of pacemakers, and this may be too much surgery for some patients with prolonged CPB times. At Northwestern Medicine, we have a nuanced approach that matches the patient and the primary operation with the ablation and LAA treatment (Table 1). The basic first step is to close the LAA, which we routinely do with a clip. The majority of our patients then receive an LA lesion set (modeled after the maze III) using cryoablation. Select patients with right side involvement receive right-side lesions. Near $100 \%$ of patients with mitral disease with preoperative $\mathrm{AF}$ receive ablation and LAA closure. ${ }^{34}$ Currently, about $30 \%$ have rightside ablation as well. For operations such as coronary artery bypass and aortic valve replacement without the need to open the LA, about $70 \%$ receive LAA clip and ablation. For a standard mitral valve operation with LA ablation the need for a new pacemaker has been $<1 \%$. A successful AF ablation strategy should balance the risks of ablation against the benefits. Surgeons should not approach surgical ablation as 1 operation for all patients.

\section{Conflict of Interest Statement}

Dr McCarthy has received royalties and speaking fees from Edwards Lifesciences as well as speaking fees from Atricure and Medtronic.

The Journal policy requires editors and reviewers to disclose conflicts of interest and to decline handling or reviewing manuscripts for which they may have a conflict of interest. The editors and reviewers of this article have no conflicts of interest.

\section{References}

1. Williams JM, Ungerleider MD, Lofland GK, Cox JL, Sabiston DC Jr. Left atrial isolation: new technique for the treatment of supraventricular arrhythmias. $J$ Thorac Cardiovasc Surg. 1980;80:373-80.

2. Guiraudon GM, Campbell CS, Jones DL, McLellan JL, MacDonald JL. Combined sino-atrial node atrio-ventricular node isolation: a surgical alternative to His bundle ablation in patients with atrial fibrillation. Circulation. 1985;72:220.

3. Cox JL. A brief overview of surgery for atrial fibrillation. Ann Cardiothorac Surg. 2014:3:80-8

4. Gaynor SL, Diodato MD, Prasad SM, Ishii Y, Schuessler RB, Bailey MS, et al. A prospective, single-center clinical trial of a modified Cox maze procedure with bipolar radiofrequency ablation. J Thorac Cardiovasc Surg. 2004;128:535-42.

5. McCarthy PM, Gerdisch M, Philpott J, Barnhart GR, Waldo AL, Shemin R, et al. Three-year outcomes of the postapproval study of the AtriCure bipolar radiofre- quency ablation of permanent atrial fibrillation trial. J Thorac Cardiovasc Surg. October 3, 2020 [Epub ahead of print].

6. Bakir NH, Khiabani AJ, MacGregor RM, Kelly MO, Sinn LA, Schuessler RB, et al. Concomitant surgical ablation for atrial fibrillation is associated with increased risk of acute kidney injury but improved late survival. J Thorac Cardiovasc Surg. January 23, 2021 [Epub ahead of print].

7. McCarthy PM. Commentary: are the atrial fibrillation ablation guidelines wrong? J Thorac Cardiovasc Surg. February 5, 2021 [Epub ahead of print].

8. Badhwar V, Rankin JS, Ad N, Grau-Sepulveda M, Damiano RJ, Gillinov AM, et al. Surgical ablation of atrial fibrillation in the United States: trends and propensity matched outcomes. Ann Thorac Surg. 2017;104:493-500.

9. Axtell AL, Fiedler AG, Melnitchouk S, D’Alessandro DA, Villanvicencio MA, Jassar AS, et al. Correlation of cardiopulmonary bypass duration with acute renal failure after cardiac surgery. J Thorac Cardiovasc Surg. 2020;159:170-8.

10. Gillinov AM, Gelijns AC, Parides MK, DeRose JJ Jr, Moskowitz AJ, Voisine P, et al. Surgical ablation of atrial fibrillation during mitral-valve surgery. $N$ Engl J Med. 2015;372:1399-409.

11. Haissaguerre M, Jais P, Shah DC, Takahashi A, Hocini M, Quiniou G, et al. Spontaneous initiation of atrial fibrillation by ectopic beats originating in the pulmonary veins. N Engl J Med. 1998;339:659-66.

12. Blackstone EH, Chang HL, Rajeswaran J, Parides MK, Ishwaran H, Li L, et al. Biatrial maze procedure versus pulmonary vein isolation for atrial fibrillation during mitral valve surgery: new analytical approaches and end points. J Thorac Cardiovasc Surg. 2019;157:234-43.e239.

13. Cox JL, Malaisrie SC, Churyla A, Mehta C, Kruse J, Kislitsina ON, et al. Cryosurgery for atrial fibrillation: physiologic basis for creating optimal cryolesions. Ann Thorac Surg. December 2, 2020 [Epub ahead of print].

14. Kanderian AS, Gillinov AM, Pettersson GB, Blackstone E, Klein AL. Success of surgical left atrial appendage closure: assessment by transesophageal echocardiography. J Am Coll Cardiol. 2008;52:924-9.

15. Starck CT, Steffel J, Emmert MY, Plass A, Mahapatra S, Falk V, et al. Epicardial left atrial appendage clip occlusion also provides the electrical isolation of the left atrial appendage. Interact Cardiovasc Thorac Surg. 2012;15:416-8.

16. Friedman DJ, Piccini JP, Wang T, Zheng J, Malaisrie SC, Holmes DR, et al. Association between left atrial appendage occlusion and readmission for thromboembolism among patients with atrial fibrillation undergoing concomitant cardiac surgery. JAMA. 2018;319:365-74.

17. Whitlock RP, Belley-Cote EP, Paparella D, Healey JS, Brady K, Sharma M, et al. Left atrial appendage occlusion during cardiac surgery to prevent stroke. $N$ Engl J Med. 2021;384:2081-91.

18. Churyla A, Iddriss A, Andrei AC, Kruse J, Malaisrie SC, Passman R, et al. Biatrial or left atrial lesion set for ablation during mitral surgery: risks and benefits. Ann Thorac Surg. 2017;103:1858-65.

19. Mehaffey JH, Krebs E, Hawkins RB, Charles EJ, Tsutsui S, Kron IL, et al. Variability and utilization of concomitant atrial fibrillation ablation during mitral valve surgery. Ann Thorac Surg. 2021;111:29-34.

20. Lee R, McCarthy PM, Wang EC, Vaduganathan M, Kruse J, Malaisrie SC, et al. Midterm survival in patients treated for atrial fibrillation: a propensity-matched comparison to patients without a history of atrial fibrillation. $J$ Thorac Cardiovasc Surg. 2012;143:1341-51.

21. Musharbash FN, Schill MR, Sinn LA, Schuessler RB, Maniar HS, Moon MR, et al. Performance of the Cox-maze IV procedure is associated with improved long-term survival in patients with atrial fibrillation undergoing cardiac surgery. J Thorac Cardiovasc Surg. 2018;155:159-70.

22. McCarthy PM, Manjunath A, Kruse J, Andrei AC, Li Z, McGee EC Jr, et al. Should paroxysmal atrial fibrillation be treated during cardiac surgery? J Thorac Cardiovasc Surg. 2013;146:810-23.

23. Iribarne A, DiScipio AW, McCullough JN, Quinn R, Leavitt BJ, Westbrook BM, et al. Surgical atrial fibrillation ablation improves long-term survival: a multicenter analysis. Ann Thorac Surg. 2019;107:135-42.

24. Rankin JS, Grau-Sepulveda MV, Ad N, Damiano RJ Jr, Gillinov AM, Brennan JM, et al. Associations between surgical ablation and operative mortality after mitral valve procedures. Ann Thorac Surg. 2018;105:1790-6.

25. Ad N, Suri RM, Gammie JS, Sheng S, O'Brien SM, Henry L. Surgical ablation of atrial fibrillation trends and outcomes in North America. J Thorac Cardiovasc Surg. 2012;144:1051-60.

26. DeRose JJ Jr, Mancini DM, Chang HL, Argenziano M, Dagenais F, Ailawadi G, et al. Pacemaker implantation after mitral valve surgery with atrial fibrillation ablation. J Am Coll Cardiol. 2019;73:2427-35.

27. Cox JL, Ad N, Churyla A, Malaisrie SC, Pham DT, Kruse J, et al. The maze procedure and postoperative pacemakers. Ann Thorac Surg. 2018;106:1561-9. 
28. Lee R, Vassallo P, Kruse J, Malaisrie SC, Rigolin V, Andrei AC, et al. A randomized, prospective pilot comparison of 3 atrial appendage elimination techniques: internal ligation, stapled excision, and surgical excision. J Thorac Cardiovasc Surg. 2016;152:1075-80.

29. Salzberg SP, Plass A, Emmert MY, Desbiolles L, Alkadhi H, Grunenfelder J, et al. Left atrial appendage clip occlusion: early clinical results. J Thorac Cardiovasc Surg. 2010;139:1269-74.

30. Ailawadi G, Gerdisch MW, Harvey RL, Hooker RL, Damiano RJ Jr, Salamon T, et al. Exclusion of the left atrial appendage with a novel device: early results of a multicenter trial. J Thorac Cardiovasc Surg. 2011;142:1002-9.e1001.

31. Malaisrie SC, Lee R, Kruse J, Lapin B, Wang EC, Bonow RO, et al. Atrial fibrillation ablation in patients undergoing aortic valve replacement. J Heart Valve Dis. 2012;21:350-7.

32. Cappabianca G, Ferrarese S, Tutino C, Corazzari C, Matteucci M, Mantovani V, et al. Safety and efficacy of biatrial vs left atrial surgical ablation during concomitant cardiac surgery: a meta-analysis of clinical studies with a focus on the causes of pacemaker implantation. J Cardiovasc Electrophysiol. 2019;30: 2150-63.

33. Damiano RJ Jr, Badhwar V, Acker MA, Veeragandham RS, Kress DC Robertson JO, et al. The CURE-AF trial: a prospective, multicenter trial of irrigated radiofrequency ablation for the treatment of persistent atrial fibrillation during concomitant cardiac surgery. Heart Rhythm. 2014;11:39-45.

34. Desai A, Thomas JD, Bonow RO, Kruse J, Andrei AC, Cox JL, et al. Asymptomatic degenerative mitral regurgitation repair: validating guidelines for early intervention. J Thorac Cardiovasc Surg. 2021;161:981-94.e985.

Key Words: atrial fibrillation surgery, Cox maze, maze IV, atrial fibrillation cryoablation, atrial fibrillation surgery lesion set 